\title{
Design of an intelligent rapid nozzle cleaning control system for fused deposition modelling 3D printers
}

\author{
Wei Wei ${ }^{1}$, Ning Chen ${ }^{2}$, Jiufeng Zhang ${ }^{3}$, Xinyu Zhang ${ }^{4}$ \\ ${ }^{1}$ Shaanxi Key Laboratory of Surface Engineering and Remanufacturing, Xi'an University, No.1 Science and Technology Six \\ Road, Xi'an 710065, China \\ ${ }^{2}$ School of Mechanical and Precision Instrument Engineering, Xi'an University of Technology, No.5 South Jinhua Road, Xi'an \\ 710065, China \\ ${ }^{3}$ School of Mechanical and Materials Engineering, Xi’an University, No.1 Science and Technology Six Road, Xi'an 710065, \\ China \\ ${ }^{4}$ School of Information Engineering, Xi'an University, No.1 Science and Technology Six Road, Xi'an 710065, China
}

Corresponding Author Email: zhangxinyu1112@sina.com

https://doi.org/10.18280/ijht.360236

Received: 15 September 2017

Accepted: 5 February 2018

Keywords:

FDM, DSC, nozzle cleaning, 3D printer

\begin{abstract}
This paper aims to overcome the poor effect and slow speed of traditional cleaning methods for clogged nozzles of the fused deposition modelling (FDM) 3D printers. For this purpose, a high-temperature melting experiment was carried out on thermoplastics, and a thermal analysis was performed by fitting the differential scanning calorimetry (DSC) curve was fitted by cubic spline interpolation. On this basis, an intelligent, rapid nozzle cleaning control system was developed considering the physical cleaning method. The system was applied to clean the clogged nozzle of an actual FDM printer. The results show that the system can complete the cleaning task rapidly without damaging the nozzle. The control system works stably, automatedly and conveniently, providing a guarantee for the effective and timely operation of FDM printers. The research findings shed new light on the application and promotion of FDM 3D printers.
\end{abstract}

\section{INTRODUCTION}

Fused deposition modelling (FDM), also known as fused filament fabrication, is a $3 \mathrm{D}$ printing process that uses a continuous filament of a thermoplastic material. In daily application, this technology faces such defects as low precision, poor bearing capacity and nozzle clogging. The first two defects can be ameliorated and eliminated through selection of alternative materials and techniques and postprocessing. However, there is not yet a good solution to nozzle clogging. The printing performance of the FDM is constrained by many factors: the nozzle is relatively small, the printing material is easily deformed in damp conditions, and there is a certain degree of shrinkage in the shaping process. These constraints negatively affect the smooth extrusion of the molten material, pushing up the chance of clogging and dragging down the shaping efficiency. In severe cases, the equipment may be damaged and the safety of the operator may be jeopardized [1-4].

Currently, there are three methods to tackle nozzle clogging: 1) Manual cleaning: manually adjust the nozzle temperature to $240^{\circ} \mathrm{C}$, remove the front fan, and manually squeeze a filament into the feed tube so that the nozzle can normally extrude filament; then, pull out the filament, re-enter the feed tube, and pull out the filament again after a short while; the half-melted filament can bring out the residues in the nozzle; repeat the above steps [5]; 2) Mechanical cleaning: At room temperature, scoop up the solidified material from the nozzle with small tools (e.g. tweezer); 3) Chemical cleaning: remove the nozzle and place it into the acetone solution and clear the nozzle with
$0.3 \mathrm{~mm}$ steel wire. In actual practice, the manual cleaning rarely removes all the residues in the nozzle, the mechanical cleaning often damages the nozzle, and the chemical cleaning is harmful to the human body and extremely time-consuming (the soaking usually takes $12 \mathrm{~h}$ ). None of these methods can satisfy the efficiency requirements for $3 \mathrm{D}$ printing in an effective and timely manner [6-8]. Thus, it is very difficult to ensure the part quality and printing efficiency of FDM equipment.

The physical cleaning is a novel method that cleans the solidified materials with high-temperature and high-pressure air flow. This method overcomes all the defects of traditional approaches and guarantees the efficiency and timeliness of 3D printing [9-10]. To further enhance the temperature control of the printing device, this paper carries out a high-temperature melting experiment on the printing material and performs relevant thermal analysis. On this basis, a control system was designed for rapid and efficient cleaning.

\section{HIGH-TEMPERATURE MELTING EXPERIMENT AND THERMAL ANALYSIS}

A melting experiment was carried on thermoplastics with a high-temperature air-pressure gun, aiming to disclose the melting features of thermoplastics and realize accurate temperature control for physical cleaning [11]. The experimental results are recorded in Table 1 . The results show that the thermoplastics began to soften at $160^{\circ} \mathrm{C}$ and started to melt at $180^{\circ} \mathrm{C}$, under which the melting can be accelerated by 
Table 1. Results of melting experiment

\begin{tabular}{|c|c|c|}
\hline Temperature $\left(\mathrm{T} /{ }^{\circ} \mathrm{C}\right)$ & Time point $(\mathrm{t} / \mathrm{s})$ & $\begin{array}{l}\text { Phenomena } \\
\end{array}$ \\
\hline 160 & 15 & The thermoplastics began to soften; the heated part sagged but not melted. \\
\hline 170 & 20 & The thermoplastics was obviously softened; the heated part sagged but not melted. \\
\hline 180 & 30 & $\begin{array}{c}\text { The softening and sagging intensified; the central part of the thermoplastics was } \\
\text { liquefied. }\end{array}$ \\
\hline 190 & 35 & The softening was relatively fast; the liquefied part expanded. \\
\hline 200 & 40 & The softening was extremely fast; the thermoplastics was almost completely liquefied. \\
\hline 210 & 50 & $\begin{array}{l}\text { The thermoplastics softened and sagged rapidly; the liquefication picked up speed; the } \\
\text { melting area was of medium size. }\end{array}$ \\
\hline 220 & 60 & The liquefication was relatively fast; the melting area expanded. \\
\hline 230 & 65 & iquefication was extremely fast; the heated part was completely melted. \\
\hline
\end{tabular}

For given $N+1$ function values $y_{0}, y_{1}, \ldots, y_{N}$, the cubic spline function in the subinterval $\left[x_{i-1}, x_{i}\right](i=1,2, \ldots, N)$ can be expressed as Eq(1).

$$
\begin{aligned}
f(x)= & M_{i-1} \frac{\left(x_{i}-x\right)}{6 h_{i}}+M_{i} \frac{\left(x-x_{i-1}\right)^{3}}{6 h_{i}}+\left(y_{i-1}-\frac{M_{i-1} h^{2}}{6}\right) \frac{x_{i}-x}{h_{i}} \\
& +\left(y_{i-1}-\frac{M_{i} h_{i}^{2}}{6}\right) \frac{x-x_{i-1}}{h_{i}}
\end{aligned}
$$

where $M i$ is the second derivative $(i=0,1,2, \ldots, N)$ of the interpolation function on the $i$-th node and an undetermined parameter; $h_{i}=x_{i}-x_{i-1}$. To calculate the undetermined parameter, the continuity and end conditions of $f^{\prime}(x)$ at the nodes should be considered, forming $N+1$ functions. Here, the first derivative can be used as the boundary condition:

$$
f^{\prime}\left(x_{0}\right)=y_{0}^{\prime}, f^{\prime}\left(x_{N}\right)=y_{N}^{\prime}
$$

The unknown terms $M_{0}, M_{1}, \ldots, M_{N}$ can be derived from the $N+1$-order linear equation set, which is expressed by the following matrix:

$$
\left[\begin{array}{c}
2 \lambda_{0} \\
\mu_{1} 2 \lambda_{1} \\
\mu_{2} 2 \lambda_{2} \\
\vdots \\
\mu_{N-2} 2 \lambda_{N-2} \\
\mu_{N-1} 2 \lambda_{N-1} \\
\mu_{N} 2
\end{array}\right]\left[\begin{array}{c}
M_{0} \\
M_{1} \\
M_{2} \\
\vdots \\
M_{N-2} \\
M_{N-1} \\
M_{N}
\end{array}\right]=\left[\begin{array}{c}
d_{0} \\
d_{1} \\
d_{2} \\
\vdots \\
d_{N-2} \\
d_{N-1} \\
d_{N}
\end{array}\right]
$$

The function of any subinterval can be interpolated by substituting the matrix into Eq(1). Based on the basic melting data, the differential scanning calorimetry (DSC) curve was fitted by cubic spline interpolation (Figure 1). The wax melting point (WMP) is the initial temperature corresponding to the point that the DSC curve deviates from the lowtemperature baseline towards the first endothermic peak, while the peak wax melting temperature (PWMT) is the temperature corresponding to the top of the endothermic peak [12]. As shown in Figure 1, the WMP and PWMT of the sample were $176.1^{\circ} \mathrm{C}$ and $227.2^{\circ} \mathrm{C}$, respectively. Judging by the melting features, the solidified materials in the nozzle can be removed effectively when the air temperature was controlled between $220^{\circ} \mathrm{C}$ and $230^{\circ} \mathrm{C}$.

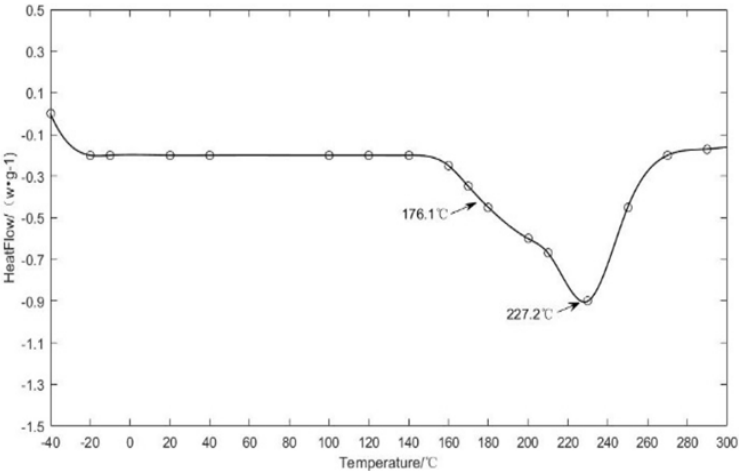

Figure 1. Fitted DSC curve

\section{HARDWARE DESIGN OF CONTROL SYSTEM}

The control system is mainly responsible for collecting and controlling the temperature of the air flow around the nozzle during the cleaning process. In light of this, the control system was designed with the following hardware: a power module, a microprogrammed control unit (MCU) module, a temperature detection module, a temperature display module, a working condition display module, a heating module, an alarm module, a wind speed control module and a cooling module (Figure 2). The system operation covers the following steps: the system starts to supply power; the parameters are initialized; the cooling module starts to work; the heating module is turned on to slowly blow out the hot air, which pre-heats the nozzle of the $3 \mathrm{D}$ printer; the temperature acquisition module collects the nozzle temperature; the temperature data are subjected to A/D conversion and displayed on the display module; when the temperature reaches the target value, the fan speed increases to control the temperature; when the temperature surpasses the upper limit, the alarm module starts to work.

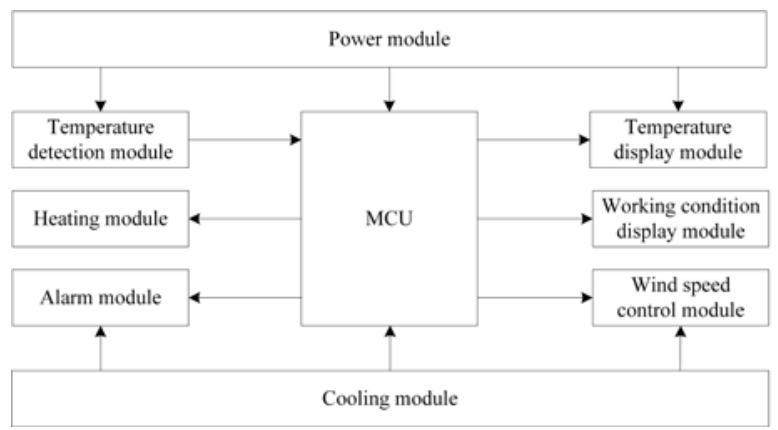

Figure 2. Hardware design of control system 


\subsection{SCM minimum system}

The system uses the STC89C52 SCM as the main controller for the operation of all hardware modules. The minimum system consists of a power supply circuit, a crystal oscillator circuit and a reset circuit. The schematic circuit diagram is shown in Figure 3.

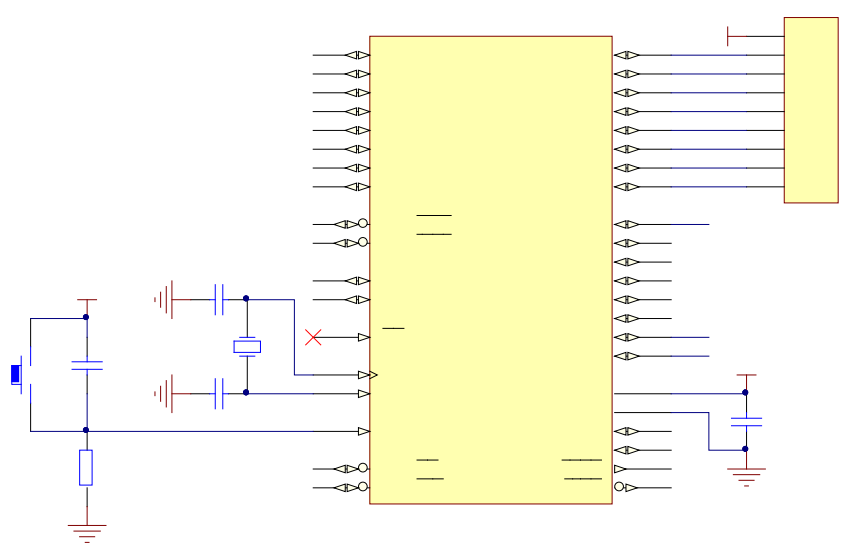

Figure 3. Schematic of the SCM minimum system

\subsection{Temperature detection module}

The temperature detection module uses a K-type thermocouple as the detection element. The temperature difference between the hot and cold terminals determines the thermoelectric potential. Cold terminal compensation is needed because the temperature varies more violently at the cold terminal than at the hot terminal. The temperature is converted by an MAX6675 chip. The thermoelectric potential generated by the K-type thermocouple is amplified and buffered to produce the thermoelectric signal U1. The cold terminal compensation generates a compensation voltage U2. Under the digital controller, the A/D conversion chip turns the $\mathrm{U} 1$ and $\mathrm{U} 2$ into digital values. The sum of U1 and U2 represents the actual temperature value $\mathrm{T}$ of the measurement point. The schematic circuit diagram of the connection between MAX6675 and STC89C52 is shown in Figure 4.

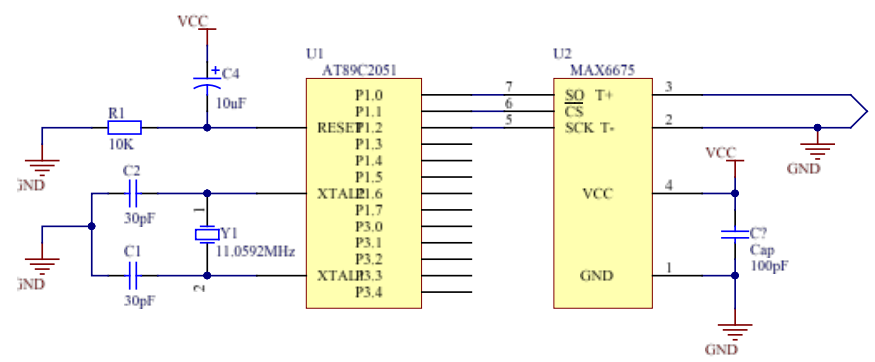

Figure 4. Schematic circuit diagram of the connection between MAX6675 and STC89C52

\subsection{Temperature display module}

Under the control of the SCM, the temperature display module displays the real-time temperature and work condition on an LCD1602 display. To facilitate operations, the I/O port of the SCM is connected directly to the display. The schematic circuit diagram of the connection between STC89C52 and LCD1602 is shown in Figure 5.

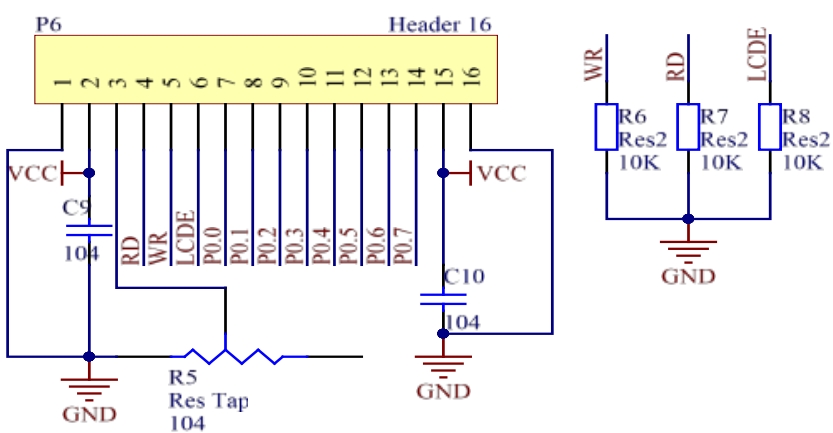

Figure 5. Schematic circuit diagram of the connection between STC89C52 and LCD1602

\subsection{Power module}

The power module should satisfy the power demand and prevent the interference between different voltages. In our system, the power is directly transmitted from the 220V supply to the transformer for step-down; then, the power is introduced to the rectifier bridge to generate DC voltage; finally, the $10 \mathrm{~V}$ DC voltage is transferred to the 7805-regulator chip to produce a $5 \mathrm{~V}$ DC voltage. The schematic circuit diagram of the power module is shown in Figure 6.

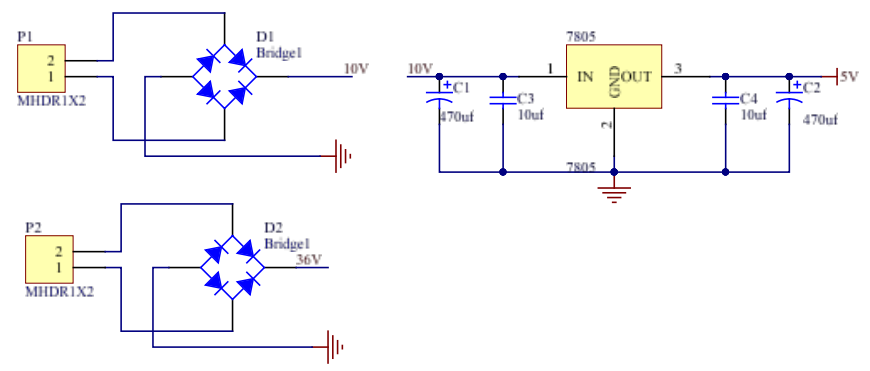

Figure 6. Schematic circuit diagram of the power module

\section{SOFTWARE DESIGN OF CONTROL SYSTEM}

The software modules were designed according to the system control requirements. The designed software modules include the main program, the temperature detection program, the temperature display program, the relay driver program, the alarm program, etc. During system operation, the temperature detection program controls the temperature, and starts the relay to heat up the modules. The I/O ports of the SCM are defined in Table 2.

Table 2. I/O ports of the SCM

\begin{tabular}{cc}
\hline I/O ports & Functions \\
\hline P0.0-P0.7 & 8-digit seven-segment LED display port \\
\hline P1.4 & Buzzer control port \\
\hline P2.0 & Relay control port \\
\hline P2.6-P2.7 & Latch control port \\
\hline P3.4-P3.6 & Temperature A/D conversion chip control port \\
\hline
\end{tabular}

The system operation covers the following steps: the main program is started; the parameters are initialized; A/D conversion subprogram of the temperature detection module and LED temperature display subprogram are invoked; the temperature value is calculated and compared to the 
temperature control requirements. If the temperature is below the required level, the system displays the current temperature; if the temperature reaches the pre-set value, the SCM calls the relay driver subprogram to change the air speed; if the temperature surpasses the alarm value, the SCM calls the alarm subprogram and displays the current temperature. The workflow of the main program is illustrated in Figure 7.

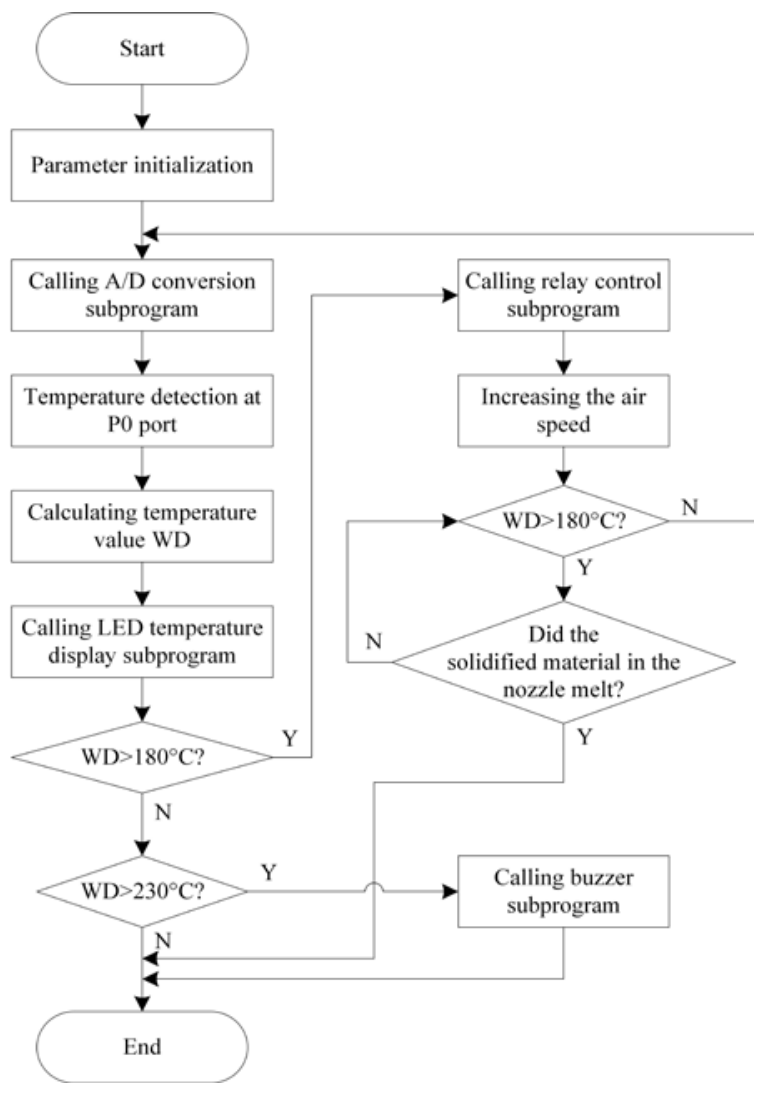

Figure 7. Workflow of the main program

\section{SYSTEM TEST}

According to the above hardware and software design, an intelligent nozzle cleaning device was assembled for FDM 3D printers (Figure 8). Software debugging and electromechanical joint debugging demonstrate that all modules can work normally, indicating that the system debugging achieved the expected results.

Then, this device was applied to clean a clogged nozzle. The experimental results are listed in Table 3. It can be seen that the solidified materials were completely melted in the cleaning experiment. However, the actual cleaning lasted 86s, longer than the $65 \mathrm{~s}$ in the high-temperature melting experiment on thermoplastics. This is attributable to the fine fissures in the nozzle. When the temperature exceeded the PWMT of $227.2^{\circ} \mathrm{C}$, the materials were all melted by the hot air and blown out of the nozzle. The experimental results are consistent with the results of the thermal analysis.

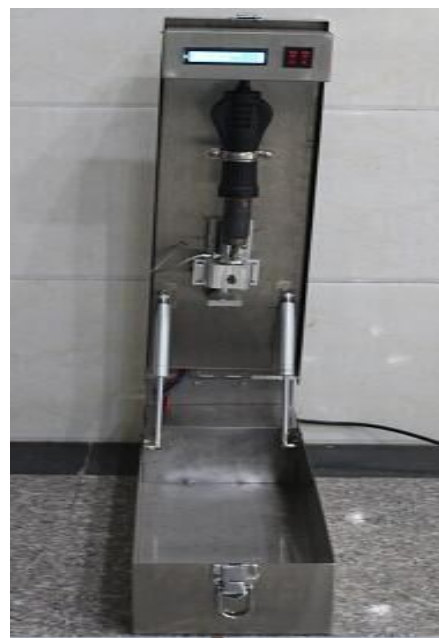

Figure 8. Intelligent nozzle cleaning device

Table 3. Results of system cleaning experiment

\begin{tabular}{|c|c|c|}
\hline Temperature $\left(\mathrm{T} /{ }^{\circ} \mathrm{C}\right)$ & Time point $(\mathrm{t} / \mathrm{s})$ & Phenomena \\
\hline 130 & 36 & The nozzle temperature increased; no obvious changes took place on the solidified materials \\
\hline 150 & 48 & $\begin{array}{l}\text { The nozzle temperature rose rapidly; the solidified materials started to soften; the relay } \\
\text { switched to the high air speed }\end{array}$ \\
\hline 170 & 58 & The solidified materials started to melt \\
\hline 190 & 68 & A few solidified materials were blown out of the nozzle \\
\hline 210 & 79 & Lots of solidified materials were blown out of the nozzle \\
\hline 230 & 86 & All solidified materials were blown out of the nozzle \\
\hline
\end{tabular}

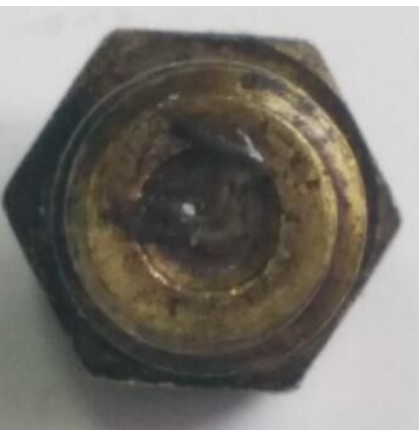

(a) Pre-cleaning

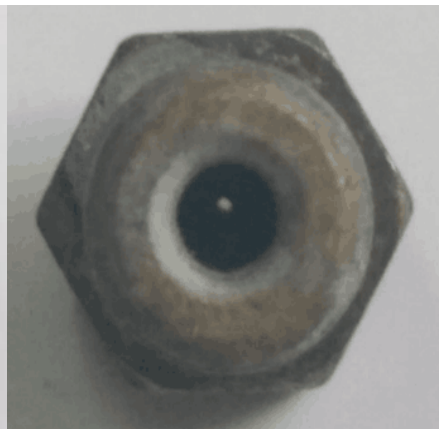

(b) Post-cleaning
Figure 9. Photos on the nozzle before and after the cleaning experiment
Figure 9 provides the photos on the nozzle before and after the cleaning experiment. It is clear that the filament outlet of the nozzle was completely clogged before the cleaning, indicating that the nozzle was not usable. After the 86s-long cleaning by high-temperature air, the solidified materials were all melted and blown out of the nozzle. The filament outlet and its surroundings became clean and clear. Suffice it to say that the cleaning achieved the desired effect.

\section{CONCLUSIONS}

Inspired by physical cleaning method, this paper designs an intelligent quick nozzle cleaning device for FDM 3D printers through high-temperature melting experiment and thermal analysis. The proposed device was applied to the cleaning of 
the nozzle of an actual FDM printer. The results show that the device can complete the cleaning in only 86 seconds. The cleaning time is greatly reduced without damaging the nozzle. The proposed cleaning device improves the efficiency and parts quality of FDM printers, and overcomes the defects of manual, mechanical and chemical cleaning methods. The control system of the device works stably, automatedly and conveniently, providing a guarantee for the effective and timely operation of FDM printers. To further bolster the precision, intelligence, universality and convenience of FDM printers, the future research will focus on transplanting and integrating the modules of our cleaning system to 3D printers and develop the online cleaning function for these printers. The research findings provide meaningful insights into the application and promotion of FDM 3D printers.

\section{ACKNOWLEDGMENT}

This article is supported by special research project of Shaanxi Provincial Department of education in 2016 (16JK2197) and 2016 national college student innovation training project (201611080006).

\section{REFERENCES}

[1] Wei W, Chen N, Xu XM, She BL. (2017). Design simulation and experimental study on nozzle cleaning stucture of FDM 3D printer. c+CA: Progress in Engineering and Science 42(4): 1342-1346.

[2] Bikas H, Stavropoulos P, Chryssolouris G. (2016). Additive manufacturing methods and modelling approaches: a critical review. International Journal of Advanced Manufacturing Technology 83: 389-405. https://doi.org/10.1007/s00170-015-7576-2

[3] Ge Q, Wang Y. (2016). Research and design of 3D printer extrusion mechanism based on FDM technology. Modern Electronics Technique 39(22): 100-107.

[4] Jin YF, Wan Y, Zhang B, Ren B. (2016). Temperature control with semiconductor refrigeration for FDM 3D printer and cooling experimental validation. Journal of Mechanical \& Electrical Engineering 33(2): 165-168.
[5] Jaya Christiyan KG, Chandrasekhar U, Venkateswarlu K. (2016). Flexural properties of PLA components under various test condition manufactured by 3D Printer. Journal of the Institution of Engineers 99(3): 363-367. https://doi.org/10.1007/s40032-016-0344-8

[6] Marudhappan R, Chandrasekhar U, Reddy KH. (2016). Optimization of simplex atomizer inlet port configuration through computational fluid dynamics and experimental study for aero-gas turbine applications. Journal of the Institution of Engineers 98(5): 595-606. https://doi.org/10.1007/s40032-016-0300-7

[7] Zhang ZQ, Wang ZL, Chen YW, Pang ZX, Wang L, Ma CC. (2016). Structural design and improvement of three jets extrusion mechanism based on FDM 3D printer. Journal of Machine Design 33(11): 56-59. https://doi.org/10.13841/j.cnki.jxsj.2016.11.012

[8] Volpato N, Kretschek D, Foggiatto JA, Gomez da Silva Cruz CM. (2015). Experimental analysis of an extrusion system for additive manufacturing based on polymer pellets. The International Journal of Advanced Manufacturing Technology 81(9-12): 1519-1531. https://doi.org/10.1007/s00170-015-7300-2

[9] Yoon HS, Lee JY, Kim HS, Kim MS, Kim ES, Shin YJ, Chu WS, Ahn SH. (2014). A comparison of energy consumption in bulk forming, subtractive, and additive processes: Review and case study. International Journal of Precision Engineering and Manufacturing-Green Technology 1(3): 261-279. https://doi.org/10.1007/s40684-014-0033-0

[10] Zhang XP, Su JQ, Gao J. (2015). 3D printing technology and its development in China. Information Technology \& Standardization (6): 17-21. https://doi.org/10.3969/j.issn.1671-539X.2015.06.005

[11] Li XY, Zhang W, An Y, Chen SQ, Zhang JX. (2017). Study on the characteristics of wax deposition in oil gathering pipelines by DSC thermal analysis. Contemporary Chemical Industry 46(6): 11091111+1115. https://doi.org/10.13840/j.cnki.cn211457/tq.2017.06.024

[12] He W, Du XP, Ma HZ, Hui XY, Sun XF. (2014). Measurement and analysis of phase transformation temperature of TC4 titanium alloy. Physical Testing and Chemical Analysis (Part A:Physical Testing) 50(7): 461464. 